\title{
Frontières
}

\section{Que les os et la peau ?}

\section{Diane Laflamme}

Volume 23, numéro 2, printemps 2011

Enquêtes sur le cadavre : 2. Fantastique

URI : https://id.erudit.org/iderudit/1007581ar

DOI : https://doi.org/10.7202/1007581ar

Aller au sommaire du numéro

Éditeur(s)

Université du Québec à Montréal

ISSN

1916-0976 (numérique)

Découvrir la revue

Citer ce document

Laflamme, D. (2011). Que les os et la peau ? Frontières, 23(2), 3-4.

https://doi.org/10.7202/1007581ar

Ce document est protégé par la loi sur le droit d'auteur. L'utilisation des services d'Érudit (y compris la reproduction) est assujettie à sa politique d'utilisation que vous pouvez consulter en ligne.

https://apropos.erudit.org/fr/usagers/politique-dutilisation/
Cet article est diffusé et préservé par Érudit.

Érudit est un consortium interuniversitaire sans but lucratif composé de l’Université de Montréal, l'Université Laval et l'Université du Québec à Montréal. Il a pour mission la promotion et la valorisation de la recherche. https://www.erudit.org/fr/ 


\section{QUE LES OS ET LA PEAU?}

Diane Laflamme, Ph.D.

Codirectrice et rédactrice en chef.

Ce second numéro que Frontières consacre à des enquêtes sur le cadavre ne parle pas que d'os et de peau. Il y mêle le fantastique. Que peuvent bien avoir à nous dire les créatures fantastiques évoquées dans ces textes, avec leurs os trop apparents et leur peau répugnante?

Commençons par interroger une créature moins effrayante: un loup qui parle. C'est le pauvre loup de Jean de La Fontaine; il n'a que les os et la peau mais il refuse qu'on passe un collier à son maigre cou en échange de quelques repas. Il court encore, si l'on en croit la conclusion de la fable! Voici deux extraits de la fable «Le loup et le chien » : «Un Loup n'avait que les os et la peau, Tant les chiens faisaient bonne garde. Ce Loup rencontre un Dogue aussi puissant que beau, Gras, poli, qui s'était fourvoyé par mégarde. [...] Attaché? dit le Loup: vous ne courez donc pas Où vous voulez? Pas toujours, mais qu'importe? Il importe si bien, que de tous vos repas Je ne veux en aucune sorte, Et ne voudrais pas même à ce prix un trésor. Cela dit, maître Loup s'enfuit, et court encore» (Les Fables, Livre I). Comme ce loup, nous ne sommes faits que d'os et de peau. Comme lui nous tenons à notre liberté, même s'il nous arrive de nous laisser tenter par les discours enjôleurs des «dogues» de tout acabit, puissants et beaux, gras et polis.

Cette liberté que nous réclamons, elle nous définit dans ce que nous sommes: nous sommes libres de penser. C'est à cet égard que le fantastique a quelque chose à nous apprendre. Le fantastique permet d'observer les métamorphoses de la pensée humaine. Une pensée capable de se déployer librement dans l'imaginaire, même si elle n'a que les os et la peau pour prendre son élan et que, ultimement, elle est indissociable de cela même qui l'oblige à s'élancer. Natalie Depraz décrit comme suit la liberté de l'imaginaire selon la phénoménologie husserlienne: «imaginer (phantasieren, fingieren), c'est aussi un processus d'engendrement des images que l'on peut décrire en tant que tel. Dès lors, on ne prendra pas en compte l'image physique telle qu'elle se donne en fin de compte, mais la naissance même des images dans mon esprit, et leur lien - fragile, complexe - avec les images perçues. En ce cas, je ne (re)produis pas activement une image perçue en me fondant sur mon image mentale, j'assiste passivement à l'avènement d'images en moi, qui empruntent des bribes à la perception, la recompose, s'y entrelace et s'y intrique. Je privilégie le moment d'émergence de l'imaginaire à partir du perçu, ses emprunts à ce dernier ou la création d'une scène irréductible à celui-ci. [...] l'imagination peut également être libre, auquel cas elle s'affranchit de la perception et du souvenir en s'affirmant comme un tout synthétique irréductible aux fragments perceptifs et remémorés qui n'en forment pas moins le point d'impulsion. [...] La liberté de l'imaginaire est dès lors à son acmé» (1999, Husserl, Paris, Armand Colin, p. 56-57). Les os et la peau des êtres fantastiques qui peuplent ce numéro de Frontières nous renseignent, en fait, sur notre capacité de penser, ainsi que sur les phénomènes qui peuvent se manifester lorsque souffle librement le vent de la pensée.

\section{LA CAPACITÉ DE PENSER LE FANTASTIQUE}

Vampires, zombies, ogresses et compagnie sont les productions d'une pensée capable de se penser elle-même, une pensée qui s'observe dans ce qu'elle est, incluant os et peau, et qui explore audacieusement les variantes les plus fantastiques liées au fait de se vivre dans un corps. Plusieurs de ces êtres fantastiques ont été pensés avant nous par les générations qui nous ont précédés. Loin de renier ces créatures, nous nous livrons à des prouesses technologiques pour en arriver à les rendre plus présentes, pour en constituer de nouvelles, pour les regarder vivre en couleurs sur grand écran, pour leur donner une histoire, une famille, des amis, des ennemis, des péripéties en plusieurs épisodes. À mesure que nous continuons à notre tour de penser des créatures fantastiques, de les mettre en pixels ou en décibels, elles se prêtent à des interprétations plus complexes, peut-être tributaires d'angoisses liées à des dangers nouveaux, d'audaces liées à des possibilités 
d'action inédites. Le fantastique se déploie maintenant dans le virtuel. Nous pouvons, par exemple, vivre grâce à un avatar des expériences hors de portée pour un corps fait d'os et de peau. Dans les lieux de nos divertissements où nous rencontrons le fantastique, nous ne sommes plus qu'une attention fascinée, une présence attentive capable de penser toutes les audaces.

Les écrans cathodiques dont nous dépendons de plus en plus pour recevoir une maigre pitance en mots et en images sont trop souvent parasités par des vendeurs de colliers, licous, laisses et autres attaches semblables à celles que refusait le pauvre loup de Jean de La Fontaine. Ces écrans et la haute technologie à laquelle ils nous donnent accès n'en sont pas moins de superbes outils qui contribuent aux prouesses du fantastique et, par là même, à l'envol de notre pensée.

\section{L'AUDACE DES ENTREPRISES DE PENSÉE \\ PORTANT SUR LES PHÉNOMĖNES LIÉS À LA MORT}

L'existence d'une revue comme Frontières témoigne elle aussi d'une audace de la pensée: depuis bientôt vingt-cinq ans, elle invite à penser les phénomènes liés à la mort. Nos auteurs et nos lecteurs ont rendu possible une telle entreprise, interdisciplinaire dans ses visées savantes, soucieuse de faire connaître la contribution des pratiques à l'avancée des savoirs et capable d'attester de ce qui se vit au-delà des mots.
C'est d'ailleurs une attestation de cet ordre que je reconnais dans le beau texte de Sylvie Dion publié ici dans la rubrique Hors-thème. Comme l'écrit l'auteure: "Le corps éprouve précisément qu'un événement s'est passé en-deça des mots. » Le titre même du texte, en proposant la notion de "fragments", invite à faire un rapprochement avec les «fragments perceptifs » dont parle Depraz quand elle décrit «le moment d'émergence» d'un imaginaire libre. Les entreprises de pensée se déploient dans un vaste espace de liberté.

La production d'une revue, en version papier et en version numérique, n'en demeure pas moins assujettie à diverses contraintes. Les lois du marché, les exigences des organismes subventionnaires et la logique des institutions obligent Frontières à explorer de nouvelles façons de demeurer présente pour nos lecteurs, à moindre coût. Ainsi, les deux numéros de nos «Enquêtes sur le cadavre» seront probablement les derniers à offrir sur papier toutes les rubriques auxquelles notre lectorat est habitué. Rien ne sera perdu pour autant; si le matériel est ainsi déplacé, ce sera pour le rendre plus largement accessible sur le site Web de la revue. On pourrait même imaginer que nous en viendrons un jour à la version iPad. Après un quart de siècle d'existence, la revue Frontières n'a peut-être que les os et la peau, mais elle n'en est pas à sa première audace!

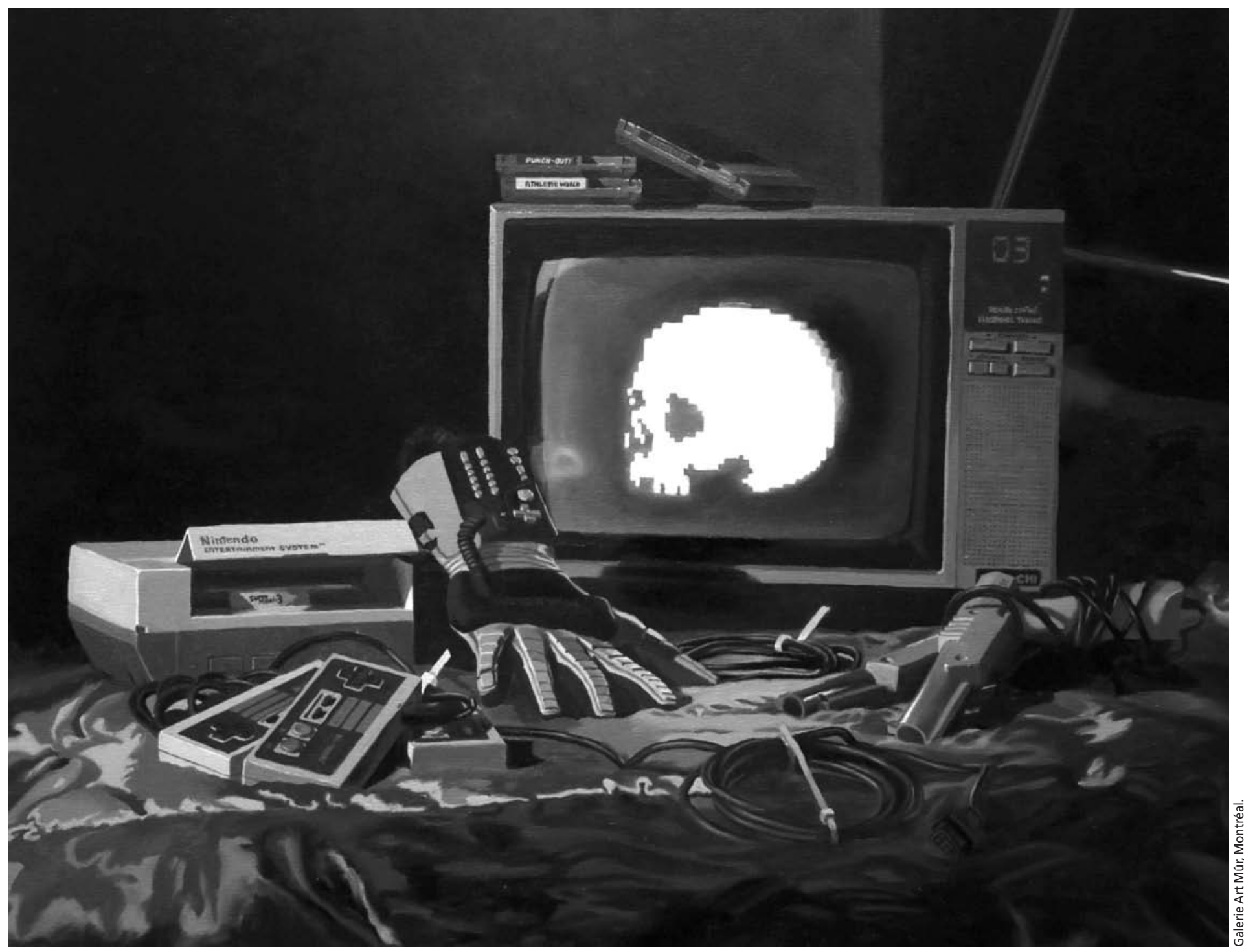

Julien Boily, Vanité de jeux vidéo, 2009, huile sur toile, $58 \times 71 \mathrm{~cm}$. 